\title{
The Application Level of Institutional Governance in the Islamic Institutions and Banks in Kuwait
}

\section{Mohammad M. Alazemi}

International Islamic University Malaysia

IIUM Institute of Islamic Banking and Finance,

Malaysia.

Email: mr.malazemi@gmail.com

\section{Abdel Majeed Al Omari}

International Islamic University Malaysia,

Malaysia.

Email: alamri@iium.edu.my

Received July, 2020; Accepted September, 2020

Abstract: This study aims to identify the governance principles and their level of applicability in the context of Islamic banks in Kuwait. The descriptive-analytical approach was used by designing a questionnaire composed of 29 questions. The study mainly addresses specific governance principles that differentiate Islamic banks from conventional ones. Findings indicate a medium application level of the governance principles in the Islamic banks of Kuwait, noting that there are deficiencies in some aspects, which is the absence of disclosure and transparency requirements of Islamic financial operations that distinguish Islamic banks from other traditional banks. Additionally, the findings show a lack of equity in the salaries and wages scale compared to competitive banks and institutions in Kuwait.

Keywords: Islamic Banks, Financial Institutions, Governance, Kuwait

Type: Research paper

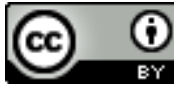

This work is licensed under a Creative Commons Attribution 4.0 International License.

\section{DOI: 10.51325/ijbeg.v3i3.58}

$$
\text { مدى تطبيق الحوكمة المؤسسية في المؤسسات والمصارف الإسلامية في الكوبت }
$$

تهدف هذه الدراسة إلى التعرف على مبادئ حوكمة البنوك الإسلامية وقياس درجة تطبيق هذه المبادئ في البنوك الإسلامية. ولتحقيق أهداف الدراسة تم تغطية الجانب النظري للدراسة من خلال الاطلاع على الكتب والمجلات والدوريات والدراسات العلمية ذات العلاقة، ومن ناحية أخرى تم تغطية الجانب الميداني للدراسة من خلال اتباع المنهج التحليلي الوصفي، وذلك من خلال تصميم استمارة استبيان مكونة من 29 سؤالاً، تغطي معظم مبادئ حوكمة المصارف الإسلامية، وبما يتتاسب مع طبيعة تمييزها عن البنوك التقليدية الأخرى. وتوصلت الدراسة إلى أن مستوى تطبيق البنك الإسلامي لمبادئ وقواعد الحوكمة هو بمستوى متوسط، مع ملاحظة أن هناك قصوراً فى بعض الجوانب، وذلك يتمثل فى عدم وجود متطلبات الإفصاح والثفافية للعمليات المالية الإسلامية والتي تميز البنوك الإسلامية عن البنوك التقليدية الأخرى، وكذلك عدم توفر العدالة في نظام الرواتب وأجور العمال مقارنة بالبنوك والمؤسسات المنافسة. الكلمات المفتاحية: البنوك الإسلامية، المؤسسات المالية، الحوكمة، الكويت. 
ظهر مفهوم حوكمة المؤسسات منذ بضع سنوات، ويرجع ذلك إلى المتطلبات الحديثة التي أحدثتها مظاهر العولمة، وبعد الانهيار المفاجئ للعديد من الثركات والمؤسسات العالمية الكبرى، زاد الاهتمام بها وأدى ذلك إلى إلى اتخاذ بعض التدابير الهامة من قبل المهتمين وصناع القرار من أجل بلورة الأسس والمبادئ لتلافي مثل هذه الكوارث،

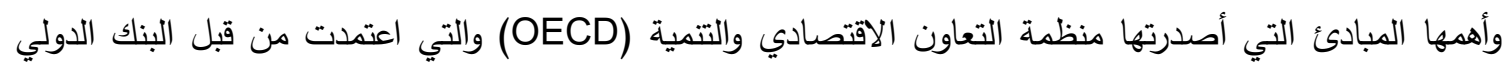
وصندوق النقد الدولي عام 1999، واتحاد هيئات أسواق المال (IOSCO) و كما تبنت لجنة بازل أيضا تلكي لتكان المعايير في نهاية نفس العام. وأصبح لحوكمة البنوك والمؤسسات المالية مكانة بارزة بسبب أهمية الخدمات المالية التي تقدمها، وحجم المخاطر

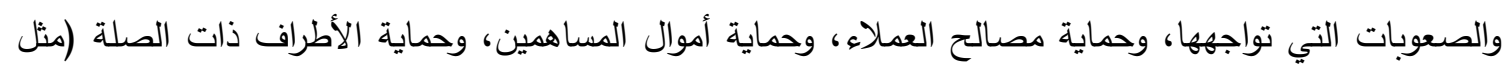

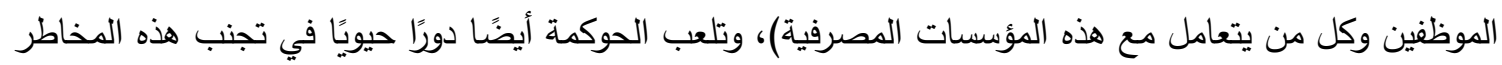

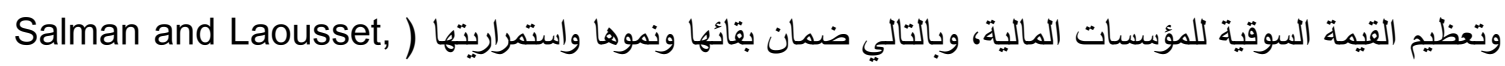
2020; Al-Naser. 2019; Alareeni, 2018) وتعتبر المؤسسات المالية الإسلامية مؤسسات مالية ذات طبيعة خاصة لأنها تلتزم بأحكام الثريعة الإسلامية، وقد

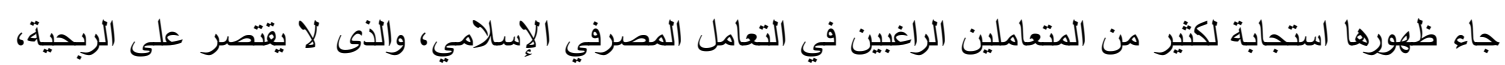

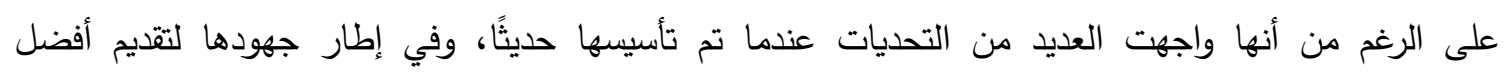
الممارسات، إلا أن المؤسسات المالية الإسلامية لا تزال ملتزمة بتطبيق الحوكمة بناءً على العديد من المبادئ التي

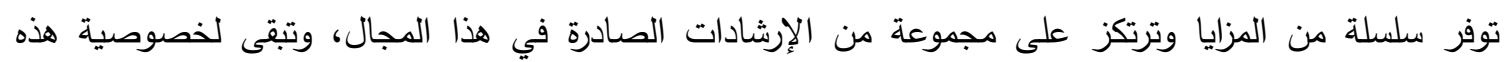
المؤسسات نتائجها في وجود تحديات تواجه تطبيقها لمبادئ الحوكمة.

مشكلة الاراسة وتساؤلاتها أرجع الباحثون فثل العديد من المشاريع إلى ضعف نظام الحوكمة المؤسسية المطبق على هذه المشاريع، حيث كثفت النتائج من خلال تحقيقاتهم في أسباب انهيار بعض المؤنسات المنسات الكبرى في شرق آسيا والولايات المتحدة الأمريكية والدول الأوروبية، على الرغم من أن ضعف نظام الحوكمة المؤسسية في مؤسسات المساهمة العامة يكاد

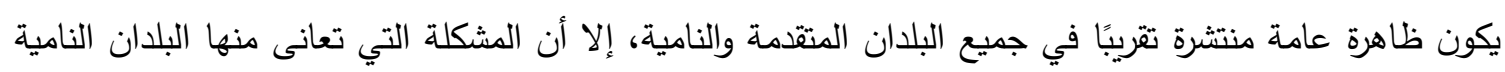

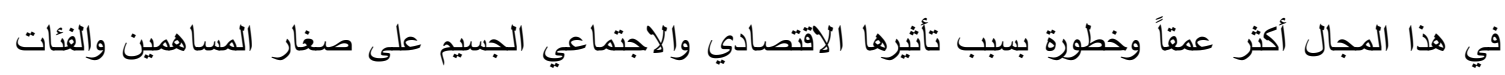
الأخرى من أصحاب المصالح. يعتبر تطبيق الحوكمة في القطاع المصرفي أكثر أهمية بالمقارنة مع القطاعات الأخرى، لأن البنوك تحتوي على

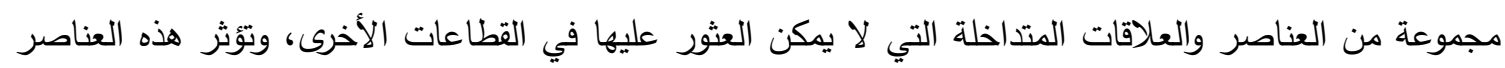

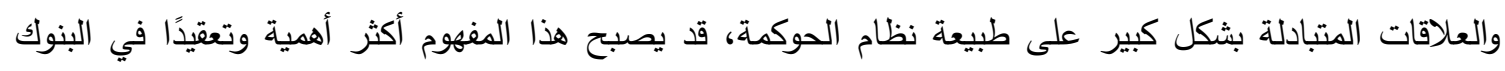
الإسلامية بسبب العمليات المصرفية المعقدة لها، والتي يختلف شكلها ومحتواها عن العمليات المصرفية التقليدية. لقد اتسمت تجارب البنوك الإسلامية أن هناك اختلالات كثيرة في التزامها بمبادئ الثريعة الإسلامية والقواعد التي سبق وضعها لها، ولذلك انتقدها كثير من الكتاب والخبراء بدعوى أنها تقوم فقط بمحاكاة لعمليات البنوك التقليدية وتحاول إيجاد الطرق لتبرير عملياتها غير الثرعية من أجل وضعها تحت إطار إسلامي في الظاهر وهناك العديد

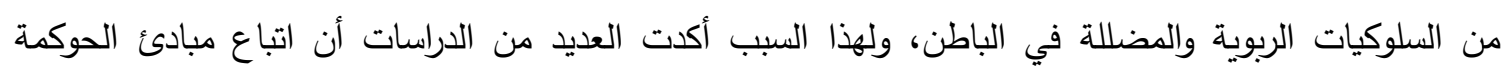


السليمة يمكن أن يوفر التدابير الاحتياطية اللازمة لمنع الفساد الإداري ويساعد في تثجيع وتعزيز الثفافية في الحياة الاقتصادية، وعليه فإنه يمكن تلخيص مشكلة الدراسة في التساؤل الرئيسي التالي:

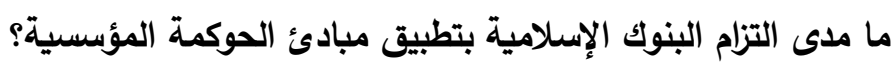
وإذا ما أخذنا بعض البنوك الإسلامية كعينة للدراسة، فإنه يمكن تمثيل العناصر الرئيسية للمشكلة بالبحث عن إجابة

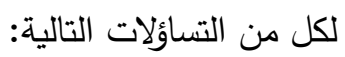

1. هل تلتزم المصارف الإسلامية بالحفاظ على حقوق المساهمين ومعاملاتهم معاملة عادلة ومتكافئة؟ 2. هل تحدد اللوائح والنظم في الدصارف الإسلامية بوضوح صلاحيات ومسئوليات مجلس الإدارة، والإدارات

$$
\text { التنفيذية، وهيئات الرقابة الثرعية؟ هن فئج }
$$

3. هل تلتزم المصارف الإسلامية بتوفير متطلبات الإفصاح والثفافية بالنسبة للبيانات المالية المنشورة؟

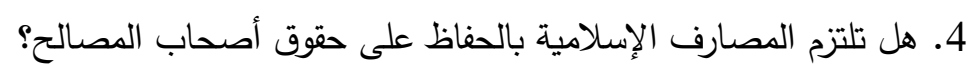

فرضيات الدراسة

للإجابة على التساؤلات المطروحة قمنا بصياغة مجموعة من الفرضيات بالاستتاد إلى مبادئ حوكمة الثركات

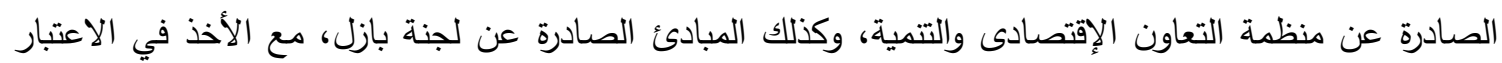
مراعاة الطبيعة المميزة للمصارف الإسلامية، وذلك كالتالي:

1. تلتزم المصارف الإسلامية بالحفاظ على حقوق المساهمين ومعاملاتهم معاملة عادلة ومتكافئة.

2. تحدد اللوائح والنظم في المصارف الإسلامية بوضوح صلاحيات ومسئوليات مجلس الإدارة، والإدارات

$$
\text { التنفيذية، وهيئات الرقابة الشرعية. }
$$

3. تلتزم المصارف الإسلامية بتوفير متطلبات الإفصاح والثفافية بالنسبة للبيانات المالية المنشورة.

$$
\text { 4. تلتزم المصارف الإسلامية بالحفاظ على حقوق أصحاب المصالح. }
$$

أهمية الدراسة

تتبع أهمية هذا الموضوع من كونه أولى المواضيع، التي تطرقت إلى مدى التزام البنوك الإسلامية بتطبيق واعتماد

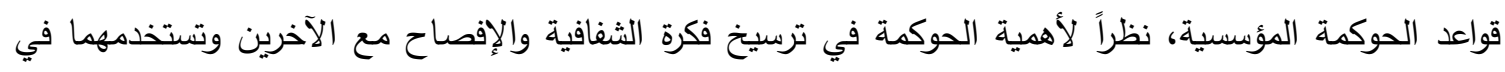
تحقيق جودة الأداء، ونظراً لأهمية قطاع البنوك الإسلامية في دعم وتطوير النمو وعجلات التتمية الاقتصادية

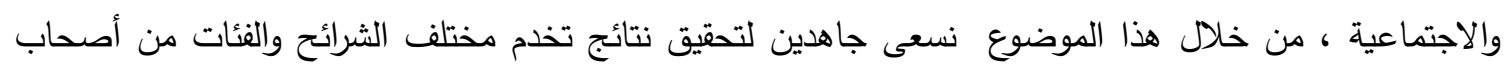
المصلحة والأطراف ذات الصلة ، سواء كانوا مساهمون أو جهات رقابية، إدارات عليا أو تتفيذية وغيرهم، وفقًا لمسماه الوظيفي والحاجة إلى هذه النتائج في اتخاذ القرار . لماء أهداف الاراسة

الغرض من هذا البحث لا يخرج عن كونه محاولة لتحقيق الأهداف التالية: • تعميم وتعميق المفاهيم والمبادئ الأساسية التي يقوم عليها نظام الحوكمة المؤسسية في البنوك الإسلامية. • معرفة مدى التزام البنوك الإسلامية بتطبيق المبادئ المتعارف عليها لنظام الحوكمة المؤسسية.

الإطار النظري والدراسات السابقة أولاً: الأطار النظري النطري تعريف الحوكمة من المنظور الشرعي الاطري جاءت الأنظمة والتشريعات بحوكمة المؤسسات من أجل تتظيم وترتيب أمورها، ويعد حفظ الحقوق من أهداف الحوكمة الأساسية وغيرها من المبادئ النبيلة، ومما هو معلوم أن الدين الإسلامي يدعم كل ما هونئ هو 
وسيلة إلى الخير شرط ألا تخالف الشرع، فإن الغايات لا تبرر الوسائل، ويكاد يجمع الباحثون حول حوكمة

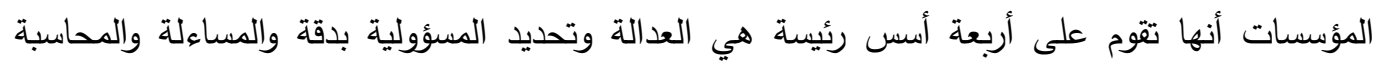

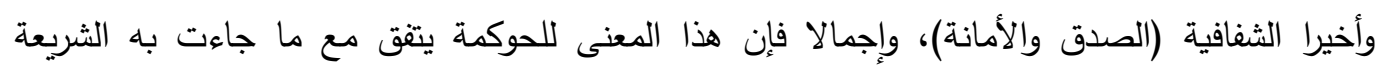

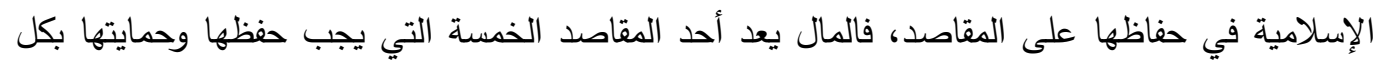

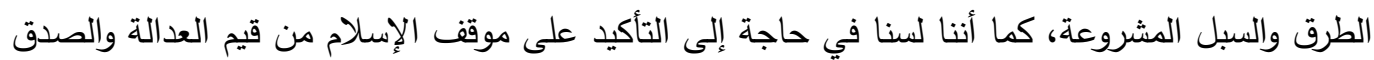
والأمانة والحث عليهما بشكل عام.

وعلى ذلك فإنه يمكن تعريف مصطلح الحوكمة في المصارف الإسلامية بأنه " ذلك النظام الذي تدار به المصارف الإسلامية إدارة رشيدة بهدف توفير المصالح وحماية الحقوق لكافة الأطراف المرتبطة بها، وتحقيق الثفافية والإفصاح عن أداء المصارف الإسلامية وفى عرض القوائم والتقارير والمعلومات المالية،

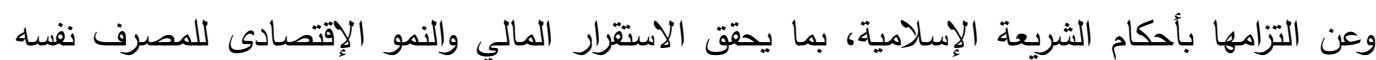
وللقطاع المصرفي الإسلامي، وكذلك تحقيق النمو الإقتصادى العام في المجتمع بل حتى تحقيق النمو لإنس الإقتصادى للأمة الإسلامية كلها".

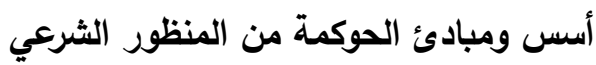
إن أسس ومبادئ حوكمة المؤسسات التي وضعتها منظمة التعاون الاقتصادي والتتمية (التي أساسها أسس الإصلاح) وهي مطلب إسلامي في الأصل، لذلك لا يمكن لأحد أن ينكر أن التجربة الإسلامية تثمل نماذج الحكم الرشيد والنظريات السياسية التي أنثئت لهذا الغرض، وقد يلتكرر عند استيفاء شروطه، ومن أهم الأسس والمبادئ

أهم الأسس التي تقوم عليها العقود الثرعية، وهو ما نجده في آيات قرآنية كثيرة، منها قوله تعالى: يَا

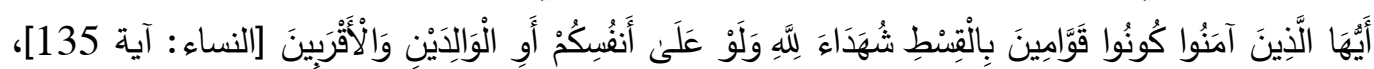

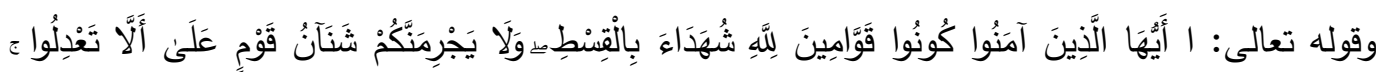

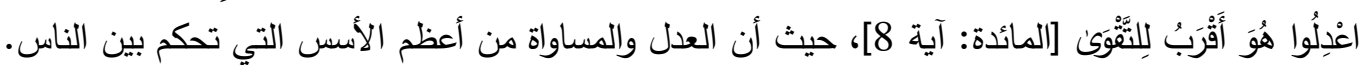

من وجهة نظر الإسلام، لا يمكن للحاكم أن يتقن صفات العدالة، ولا يمكن أن يجعلها من سمات نظام

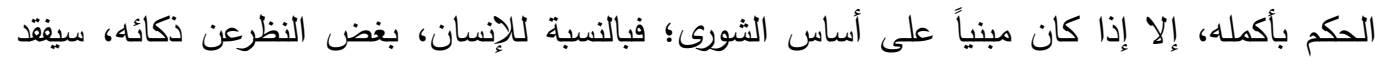

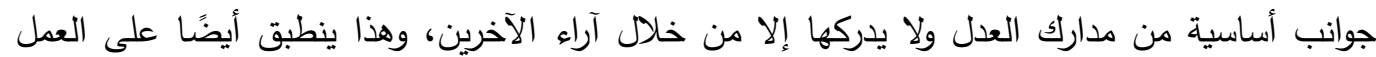

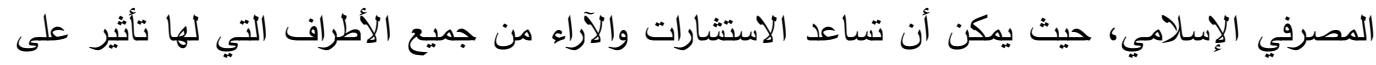

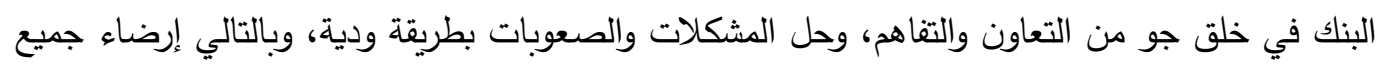
الأطراف ذات المصلحة المرتبطة بالبنك.

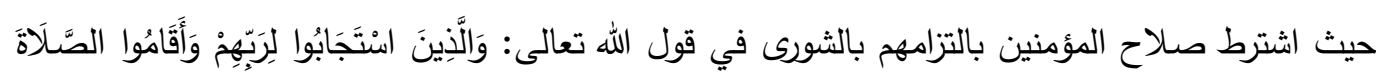

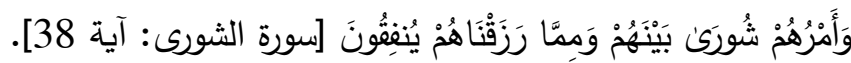

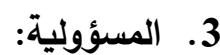

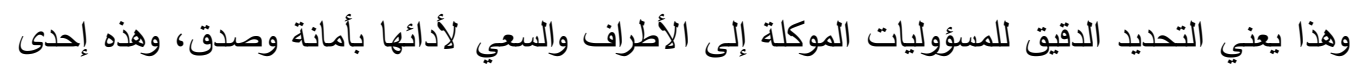

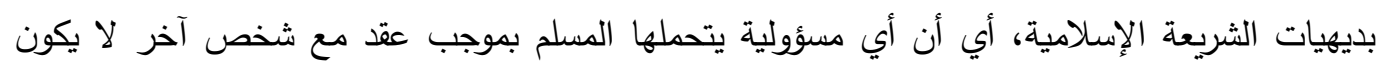


فقط مسؤولاً أمام الثخص الذي أبرم العقد معه، أنما هو سؤول أمام الله عز وجل أولاً، وهذا ما أكده الرسول صلى الله عليه وسلم عندما قال: " كلكم راع وكلكم مسؤول عن رعيته". (البخاري ومسلم)

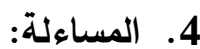

لا بد من محاسبة كل مسؤول عن التزاماته، وربط درجة الأداء بنظام للجزء الذي يكافئ المجد ويعاقب الإهمال، من خلال النظام الداخلي للمنشأة للحوافز وللعقوبات وتطبيقه على الجميع، وكذلك فإن الدانه الدولة

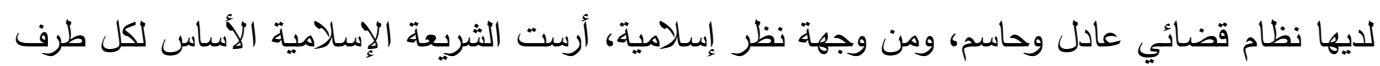

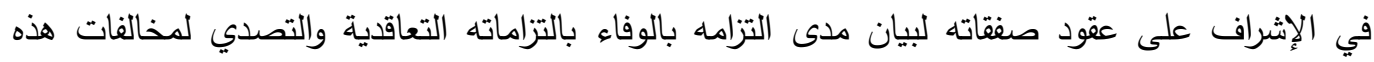
الالتزامات، وقررت عقوبات حاسمة لمن يخل بها، ولا يقتصر هذا الأمر على الجزاء الثرعي أو الإداري أو القضائي، وإنما يتعداه إلى الجزاء الإلهي. وتربات

أي الصدق والأمانة والدقة والثمولية للمعلومات المقدمة لأعمال المنشأة، بالنسبة للأطراف الذين لا لألافي تمكنهم ظروفهح من الإشراف المباشر على أعمال المنشأة التي لهم مصلحة معها، للتعرف على مدى أملى أمانة وثقة وكفاءة الإدارة، في إدارة أموالهم وحماية حقوقهم، وتمكينهم من اتخاذ القرارات السليمة في علاقاتهم

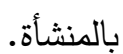

المبادئ الإرشادية لنظم الضوابط الثرعية للمؤسسات التي تقدم خدمات مالية إسلامية أصدرت لجنة الخدمات المالية الإسلامية مبادئ توجيهية حول نظام الحوكمة الشرعية للمؤسسات التي تقدم خدمات مالية إسلامية في عام 2009، هذه المبادئ هي إطار عملي لأفضل الممارسات التي ينبغي أن تتفذ من

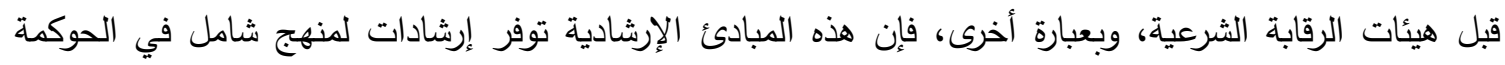

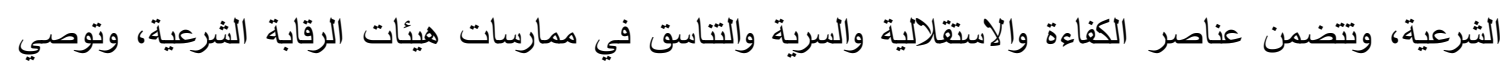
المبادئ التوجيهية لنظام الحوكمة الثرعية للمؤسسات التي تقدم خدمات مالية إسلامية بأن المؤسسات المالية

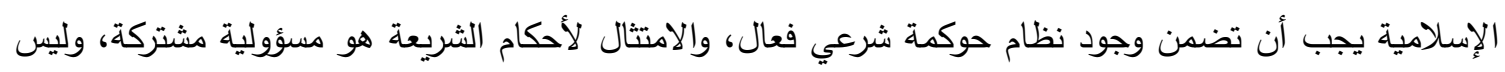

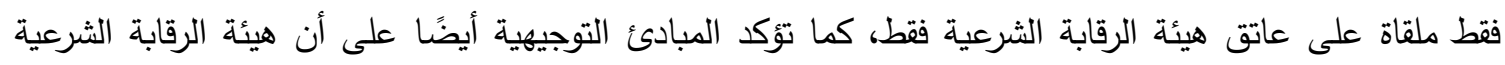

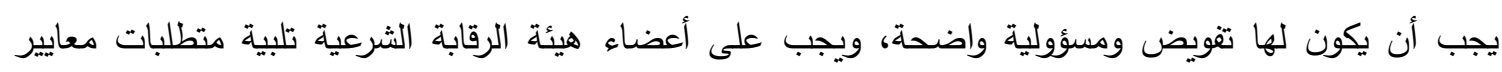

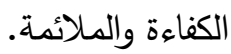

\section{معايير مجلس الخدمات المالية الإسلامية حول الحوكمة المؤسسية وائمة} إن التطور السريع للمؤسسات المالية الإسلامية فرض الحاجة إلى تنظيم الصيرفة الإسلامية لحماية الصناعة الصايه

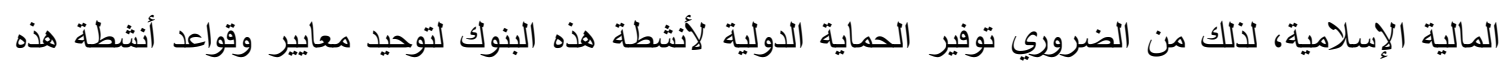

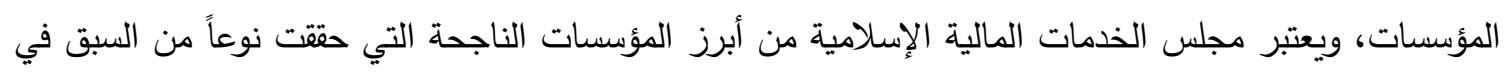
إصدار معايير ومبادئ للحوكمة المؤسسية وهي كالتالي: >

" يجب أن تضع مؤسسات الخدمات المالية الإسلامية إطارًا لسياسة رقابة إدارية شاملة تحدد الدور الاستراتيجي ووظائف كل عنصر من عناصر ضوابط الإدارة والآليات المعتمدة لموازنة مسؤوليات مؤسسات الخدمات المالية الإسلامية تجاه مختلف أصحاب المصالح: ويقصد 
بعناصر ضوابط الإدارة كل من (مجلس الإدارة واللجان المنبيقة عنه، الإدارة التتفيذية، هيئة

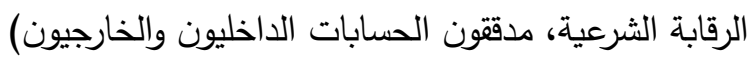
يجب أن تتبنى مؤسسات الخدمات المالية الإسلامية اعتماد التوصيات ذات التبات العلاقة التي تتضمنها معايير الرقابة الإدارية للمؤسسات المعترف بها دوليًا مثل مبادئ منظمة التعاون

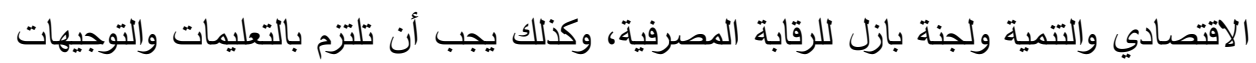
الفعالة الصادرة عن السلطات الإشرافية، كما يجب أن تلتزم بأحكام الثريعة الإسلامية ومبادئها.

يجب على مؤسسات الخدمات المالية الإسلامية التأكد من أن تقارير المعلومات المالية وغير المالية الخاصة بها تتوافق مع متطلبات معايير المحاسبة المتعارف عليها دوليًا، وتكون مطابقة الإنيات

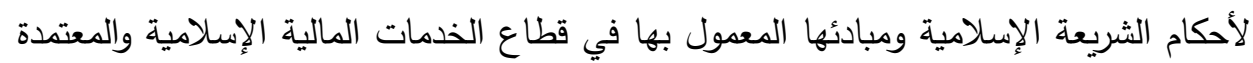

من السلطات الإشرافية فى الدول ذات الصلة، وتقديم هذه التقارير إلى مجلس الإدارة.

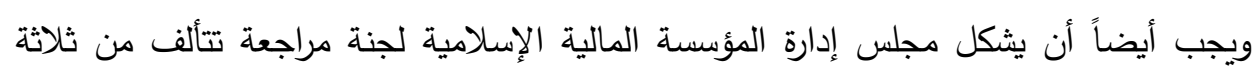
أعضاء على الأقل من مجلس الإدارة، يتم اختيارهم من بين أعضائه غير التتفيذيين المؤهلين علميًا ولديهم الخبرات المناسبة والكافية في تحليل البيانات المالية والمستندات المالية. >

يجب أن تعترف مؤسسات الخدمات المالية الإسلامية بحقوق أصحاب حسابات الاستثمار في مراقبة أداء استثماراتهم والمخاطر التي ينطوي عليها، وإنثاء وسائل لضمان الحفاظ على هذه

$$
\text { الحقوق وممارستها. }
$$

يجب على مؤسسات الخدمات المالية الإسلامية أن تتحمل مسؤولية ائتمانية تجاه أصحاب

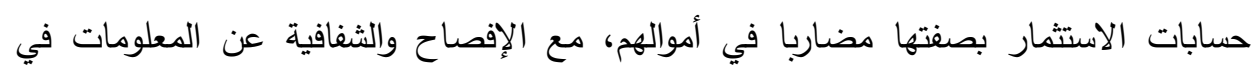

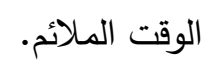

>

• يجب أن تتبنى مؤسسات الخدمات المالية الإسلامية اعتماد إستراتيجية استثمار سليمة، والتي

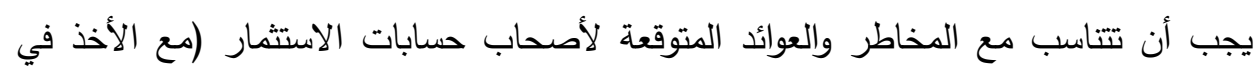
الاعتبار التميز بين أصحاب حسابات الاستثمار المقيدة وأصحاب حسابات الاستثمار المطلقة)، بالإضافة إلى اعتماد الثفافية في دعم أي مكاسب.

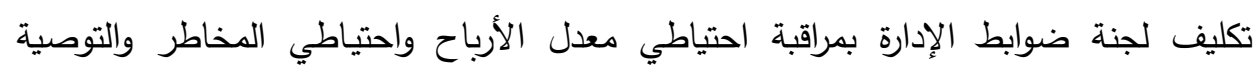
لمجلس الإدارة حول كيفية استخدامه. >

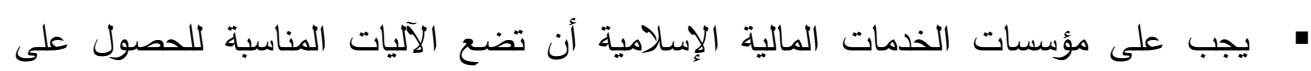

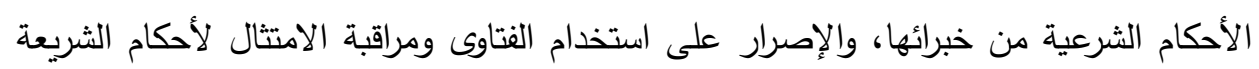

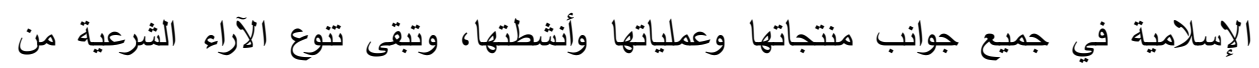
الخصائص الدائمة لقطاع الخدمات المالية الإسلامية، ويجب أن والن يتلقى المدققون الداخليون والمراقبون الثرعيون التدريب اللازم والمناسب لتحسين مهاراتهم في مراجعة مدى الالتزام بالشريعة. 
• كما يجب مواصلة إصدار وتثجيع مبادرات التنسيق بين الفتاوى الثرعية حيث أن هذا القطاع خصوصا والأمة عموما يستفيدان من الفهم المشترك والتعاون بين علماء الشريعة. >

يجب أن تلتزم شركات الخدمات المالية الإسلامية بقواعد ومبادئ الثريعة الإسلامية المنصوص

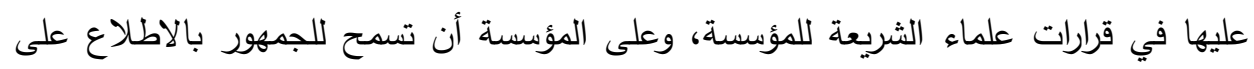
هذه القواعد والمبادئ لتشجيعهم على الاستثمار في هذه المؤسسات.

• وهذا يتطلب من مؤسسة الخدمات المالية الإسلامية أن تعتمد الثفافية عند اعتمادها تطبيق

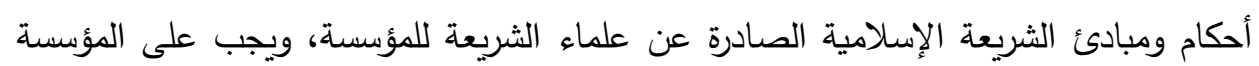

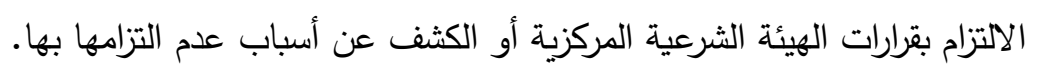

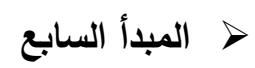
• يجب أن تزود مؤسسات الخدمات المالية الإسلامية أصحاب حسابات الاستثمار والجمهور بالمعلومات الأساسية والجوهرية حول حسابات الاستثمار التي يديرونها في الوقت المناسب الابدات وبطريقة مناسبة. • ويتطلب ذلك توفير المعلومات لأصحاب حسابات الاستثمار حول طرق حساب الأرباح وتوزيع الموجود واستراتيجية الاستثمار وآليات دعم العوائد.

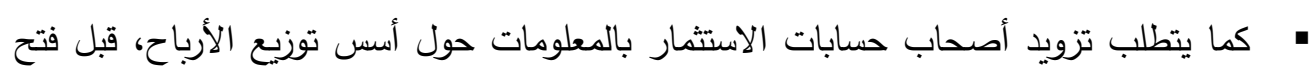

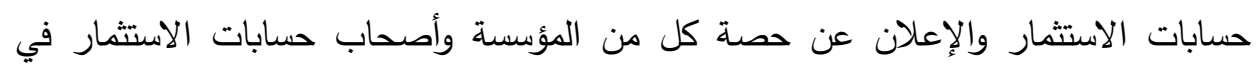

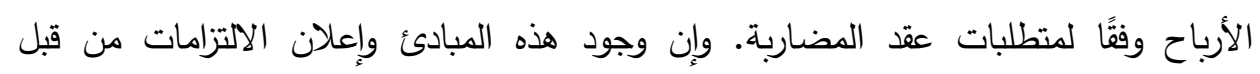

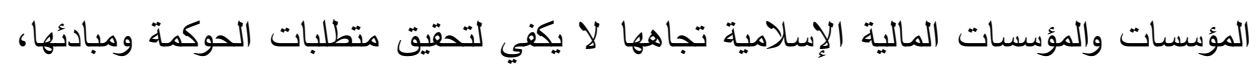

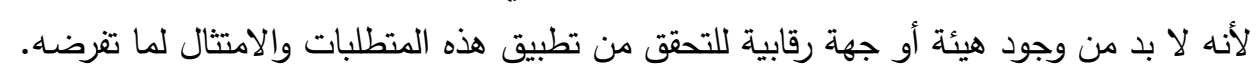

إن أهمية وجود مؤسسات تطلع بمهمة التحقق من التزام المؤسات المالية الإسلامية بالمعايير والضوابط الشرعية أصبح مطلبا ملحا، فإن وجود المعيار والضابط الثرعي وحتى العقود والنماذج الشرعية لا يعني - بالضرورة- التزام المؤسسات المالية الإسلامية العمل بمقتضاها.

من هنا جاء التفكير في إنثاء مؤسسة تطلح بمهمة التحقق من التزام المؤسسات بالمعايير والضوابط الثرعية التي تصدر عن الهيئات الثرعية لتلك المؤسسات، وتقوم بتصميم وإعداد أدلة المراجعة الثرعية وتدريب المراجعين الثرعيين على إعداد وتتفيذ برامج المراجعة الثرعية. تحديات ومعوقات حوكمة البنوك الإسلامية

إن تطبيق الحوكمة المؤسسية في البنوك الاسلامية يتطلب التغلب على بعض التحديات والمعوقات التي تواجهها في سبيل ذلك، ومن أبرزها نذكر : الفصل بين الفتوى (التشريع) والتدقيق: يوجد في كل مؤسسة مالية إسلامية هيئة خاصة للشريعة الإسلامية تتمثل مهمتها في إصدار حكم بشأن

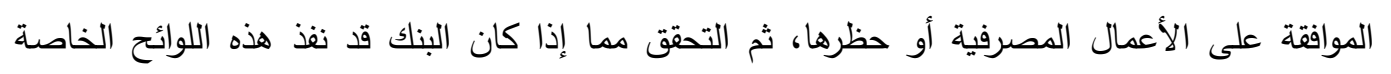
بالبنك ، على الرغم من حقيقة الجمع بين المهمتين (الفتاوى والتدقيق) الذى يحدده قوانين البنوك الإسلامية

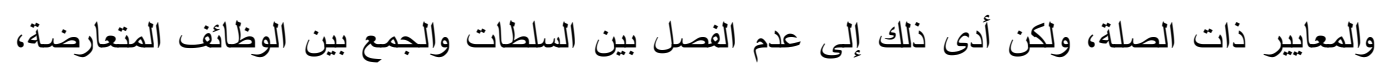


مما قد يؤدي أحيانًا إلى تغييرات في الفتوى لتتناسب مع النتائج المحتملة ، مما يضعف آلية المساءلة، الأمر الذي يتطلب الفصل بين مهام الفتوى ومهام التدقيق. توحيد المرجعية الشرعية:

يؤدي تعدد الهيئات الثرعية على مستوى كل بنك إلى تتوع مراجع الثريعة الإسلامية، مما يشكل عبنًا

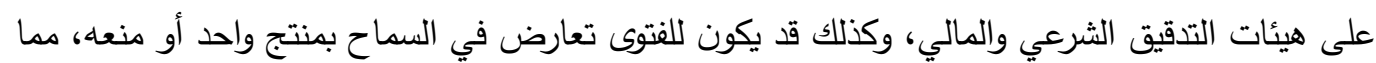
دفع البنوك إلى اختيار هيئات الفتوى القانونية المعروفة بالتيسير والتسهيل، الأمر الذي يتطلب إنشاء هيئة فتوى في كل دولة حتى تسهل عمل هيئات التدقيق الشرعي وتساعد على خلق جو المنافسة المناسب.

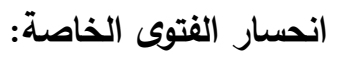

أصبح التخلي عن هيئات الفتوى الخاصة لكل بنك وإنثاء هيئة فتوى عامة في كل بلد واجبًا على المسؤول

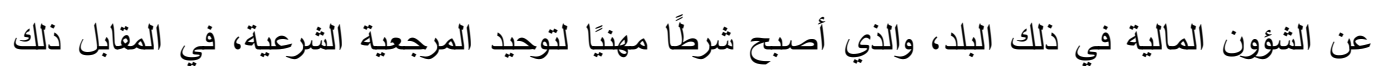
يكون هناك لكل بنك مستثار قانوني لتفسير القانون الصادر عن الهيئة العامة للفتوى. تنظيم مهمة التدقيق الثرعي: التدقيق الخارجي الثرعي ، باعتباره مهمة للهيئات الخاصة ، يعاني من العديد من أوجه القصور في

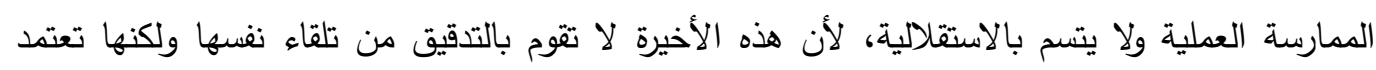

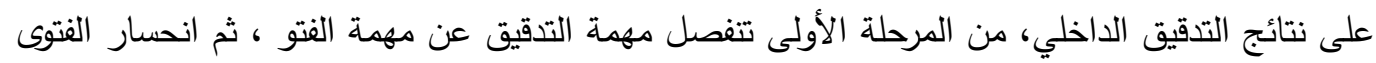

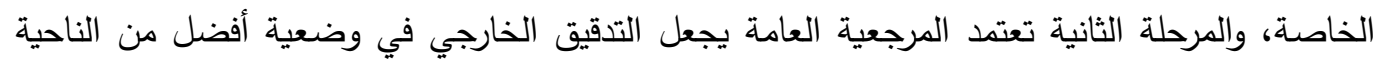
المهنية ، ومن أجل دعم استقلالية عمليات التدقيق الثرعي الخارجي، يجب تطوير نظام متكامل لإنشاء

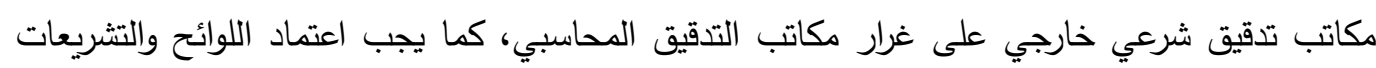
المتعلقة بمهنة التدقيق الخارجي من قبل البنوك المركزية. الالززام القانوني: إن المشكلة الحقيقية في التغلب على هذه التحديات هي إيجاد بيئة قانونية ملزمة تصدرها البنوك المركزية تجبر البنوك على تتفيذ التوصيات المذكورة أعلاه بشكل منظم، وبالتالي إنثاء نموذج عمل موحد بين التين

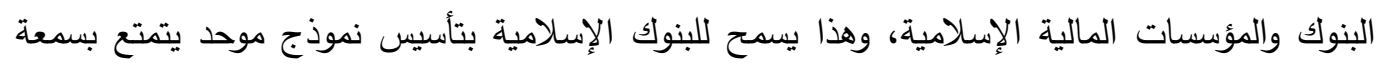
عالمية تتناقض مع الاختلافات العميقة الموجودة حاليًا ويمكنه تسويقه للدول غير الإسلامية. ثانياً: الدراسات السابقة على حد علم الباحث، وفي حدود ما توفر لديه، فإن موضوع حوكمة المؤسسات وتطبيقاتها في البنوك الإسلامية لم

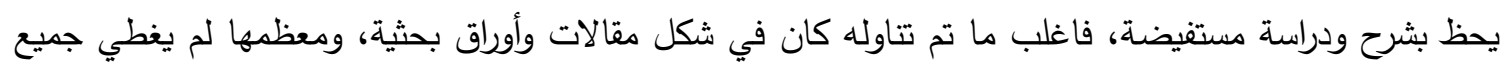

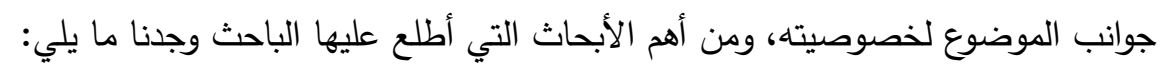
دراسة (مطر ونور،2007): بعنوان مدى التزام الثركات المساهمة العامة الأردنية بمبادئ الحوكمة المؤسسية دراسة تحليلية مقارنة بين القطاعين المصرفي والصناعي. تهدف هذه الدراسة إلى تقييم مستوى التزام الشركات الأردنية العامة بمبادئ حوكمة المؤسسات، ولتحقيق هذا الهدف

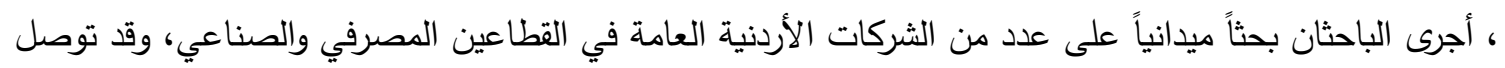

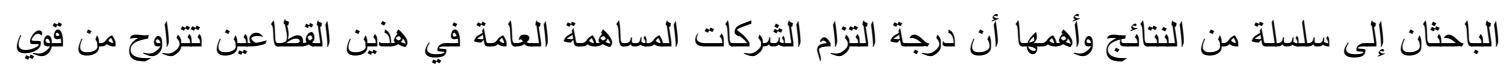
إلى ضعيف جداً، والنظام به عيوب في تطبيقه ، والسبب الجذري هو أن مجلس الإدارة لا يلتزم بقواعد السلوك 
المهني، وتوصلت الدراسة إلى مجموعة من التوصيات، ربما كان أهمها تبادر جهات الرقابة والأشراف بشأن هذه الثركات لإصدار دليل يشرح المبادئ الأساسية لنظام حوكمة المؤسسات.

دراسة (بادن ،2008): بعنوان دور حوكمة النظام المصرفي في الحد من الأزمات المالية وإلمصرفية. توصل الباحث إلى مجموعة من النتائج أهمها أن النظام المصرفي الجزائري ينقام ينقم إلى قسمين، القسم الأول يتميز بالراحة المالية والسيولة العالية، والجزء الثاني ضعف الخدمات الثات المقدمة وعدم ثقة المستثمر الأجنبي بقدراته التمويلية،

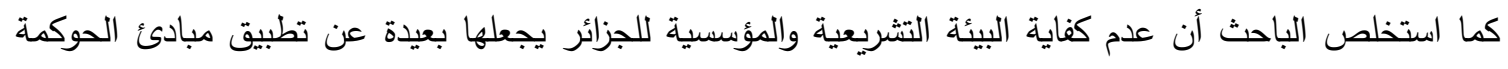
المثالية، لا سيما في النظام المصرفي. كما أكد الباحث أيضاً على أهمية دور البنك المركزي في سبيل إرساء بادئ الحوكمة في البنوك من خلال إصدار قواعد ولوائح المنظمة للمهنة، وفرض الرقابة والإشراف على لهي الأعمال المصرفية لضمان الالتزام بما يتم إصداره. دراسة (باعجاجة، 2009): بعنوان مبادئ حوكمة الثركات ومدى امكانية تطبيقها على الثركات السعودية المساهمة. تهدف هذه الدراسة إلى تثييم أنظمة حوكمة الثركات بناءً على المبادئ التي وضعتها منظمة التعاون الاقتصادي والتتمية، ودراسة إمكانية تطبيق هذه المبادئ في البيئة المحاسبية في المملكة العربية السعودية. وقد أسفرت الدراسة عن سلسلة من النتائج أهمها أن لائحة الحوكمة السعودية الصادرة عن هيئة السوق المالية تتضمن جوانب إيجابية ولكنها لم تخل من بعض نقاط الضعف، لأن بعض المؤسسات لم تطبق درجة الحوكمة المعترف بها دولياً، كما

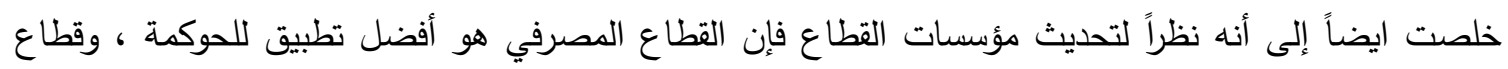

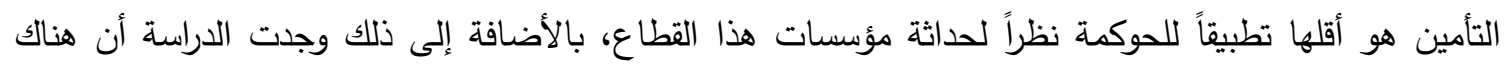

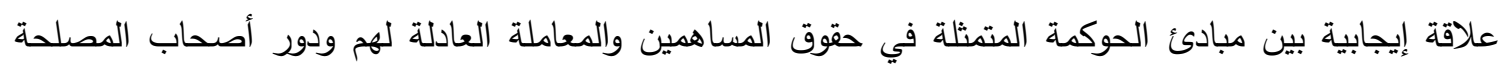
ودرجة الثفافية ومسؤوليات مجلس الإدارة.

دراسة (الهنيني وحيمور، 2013): بعنوان مدى التزام المصارف الإسلامية الاردنية بمبادئ الحاكمية المؤسسية

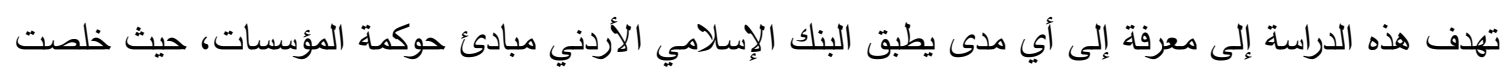
إلى أن عينة من البنوك الإسلامية العاملة في الأردن ملتزمة بمبادئ حوكمة المؤسسات المتعلقة بحماية حقوق الإن الإني

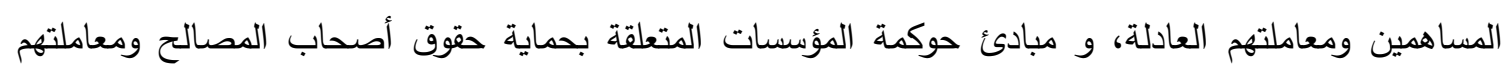
بإنصاف، كما توصلت الدراسة إلى أن هذه البنوك ملتزمة بوضع نظام يحدد صلأ صلاحيات مجلس الإدارة والإدارة

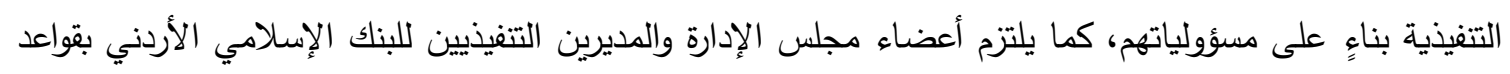

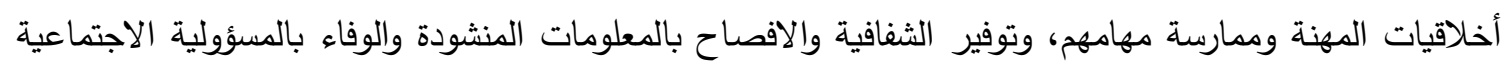

تجاه المجتمع.

دراسة (بورقبة وغربي، 2014): بعنوان أثر تطبيق حوكمة الثركات في أداء البنوك الإسلامية.

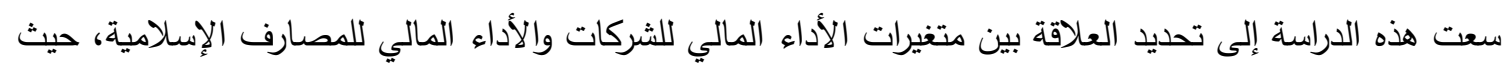

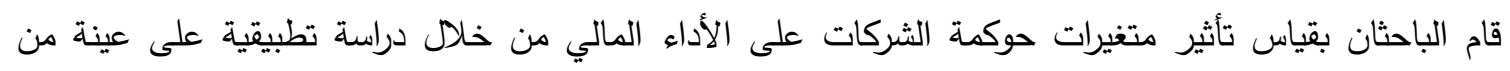

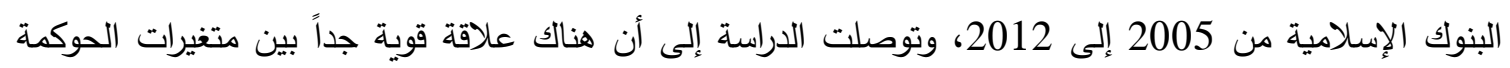

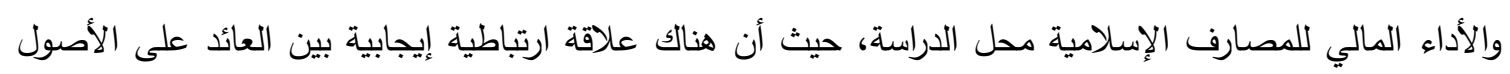

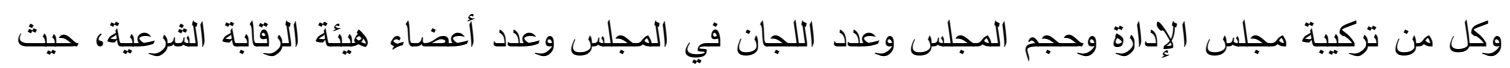


كلما زاد حجم المتغير، زاد العائد على الأصول، ويبدو أن هناك علاقة سلبية بين العائد على الأصول ومتغير تركز الملكية. ما يميز هذه الاراسة إن ما يميز هذه الدراسة- الحوكمة في مجال المؤسسات المالية والمصارف الإسلامية: دراسة ميدانية لعينة من

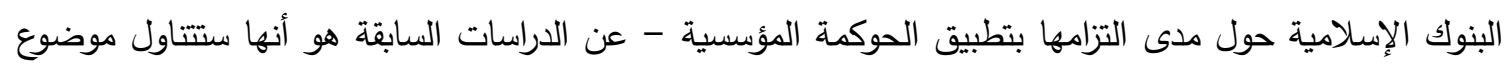
الحوكمة المؤسية في البنوك الإسلامية دون حصر لبيئة نشاط البنك، على عكس البحوث السابقة التي كانت تدرس هذا الموضوع في إطار داخلي وطني. الإطار العملي للاراسة منهجية الاراسة الميدانية تتألف الدراسة من جانبين هما الجانب النظري والجانب التطبيقي، ومن أجل تحقيق أهداف الدراسة، اعتمدنا منهجين المنهج الأستقرائى، والغرض من ذلك هو جمع وتحليل البيانات واختبار الفرضيات، والمنهج الوصفي التئي

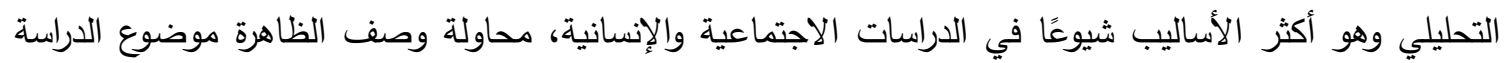
(مدى قدرة البنوك الإسلامية على تطبيق مبادئ حوكمة الثركات) وتحليل بياناتها وبيان العلاقة بين مكوناتها والآراء

التي تطرح حولها والعمليات التي تتضمنها بغية التوصل إلى نتائج منطقية تدع الفرضيات المصاغة في التئل الدراسة.

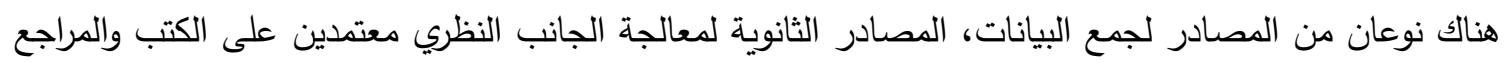
العربية والأجنبية المتعلقة بالدراسة، والمصار الأولية لمعالجة الجانب التطبيقي أو العملي من الدراسة، والتي شملت استمارة كأداة رئيسية صممت لجمع البيانات الأولية من البنوك الإسلامية المأخوذة كعينة، ليتم تفريغها وتحليل

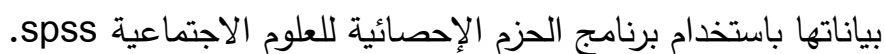
مجتمع وعينة الاراسة يتمثل مجتمع الدراسة في البنوك الإسلامية حيث تم اختيار أربعة مصارف، حيث تشمل عينة الدراسة جميع مدراء

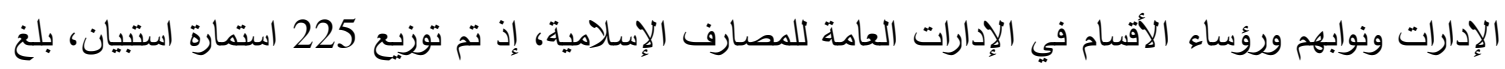

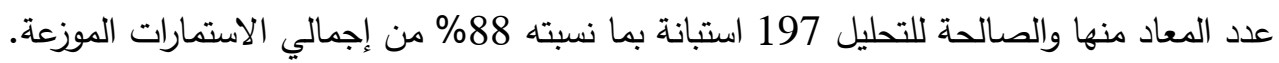

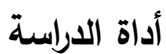

من أجل تحقيق أهداف الدراسة اعدت استمارة استبيان مخصصة لأغراض معالجة أسئلة الدراسة التي سبق عرضها،

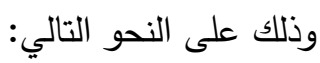
1. إعداد استبيان أولى لجمع البيانات والمعلومات. 2. الاستفادة من الدراسات السابقة في تصميم استمارة الاستبيان. 3. عرض الاستمارة على المحكمين من اجل اختبار مدى ملاءمتها لجمع البيانات.

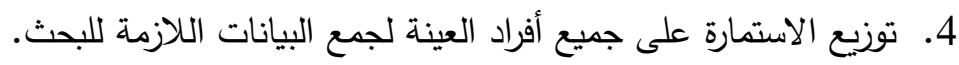
وقد تم تقسيم استمارة الاستبيان إلى جزأين هما: الجزء الأول: يختص بالبيانات والمعلومات الثخصية لأفراد عينة الدراسة، ويتضمن الوظيفة والثمانيفة والمؤل العلمي والتخصص العلمي وسنوات الخبرة العملية. الجزء الثاني: يحتوي هذا الجزء على مجموعة من 29 فقرة، إذ أن الفقرة من 1-3 تتعلق بالفرضية الأولى

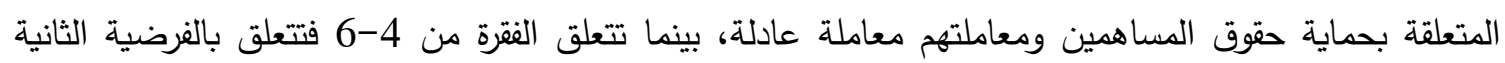
لحماية حقوق أصحاب المصالح، أما الفقرة من 7-10 فتتعلق بالفرضية الثالثة الخاصة بتوفير متطلبات الإفصاح 
والثفافية للبيانات المالية المنشورة، بينما تتضمن الفقرة من 11-29 فتتعلق بالفرضية الرابعة الذي يحدد صلاحيات ومسؤوليات مجلس الإدارة والإدارات التنفيذية وهيئات الرقابة الشرعية. تحليل البيانات الإحصائية للدراسة أجرى اختبار ألفا للتأكد ن درجة ثبات الاستبيان وصدق إجابهات للاتية العينة عليه. جدول رقم (1) يوضح نتائج اختبار ألفا لأداة البحث: الانديان

\begin{tabular}{|c|c|c|c|}
\hline درجة المصداقية & درجة الثبات & عدد الفقرات & المحاور الرئيسية \\
\hline$\% 72.4$ & $\% 52.4$ & 3 & معاملة عادلة ومتكافئة حقوق المساهمين ومعاملته \\
\hline$\% 91.5$ & $\% 83.8$ & 4 & 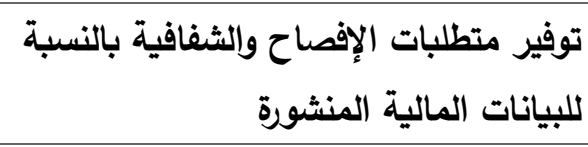 \\
\hline$\% 96$ & $\% 92.2$ & 19 & تحايل صلاحيات ومسؤوليات مجلس الإدارة \\
\hline$\% 87.8$ & $\% 77$ & 3 & الحفاظ على حقوق أصحاب المصالح \\
\hline$\% 96.9$ & $\% 93.8$ & 29 & إجمالي الاستبيان \\
\hline
\end{tabular}

يتضح من الجدول 1 أن قيمة معامل الثبات لأداة جمع البيانات بثكل عام جاءت بنسبة 93.8٪، مما يعني أن نسبة الثبات عالية، ونسبة المصداقية لإجابة العينة هي 96.9٪، مما يعني أن درجة مصداقية الإجابات مرتفعة لإنداءت جداً، والعينة متجانسة في الاستجابة على الاستبيان، وأن قابلية التعميم على مجتمع البحث ممتازة. النتائج الإحصائية للدراسة أكدت نتائج التحليل النهائية والتي تتلخص في الجدول رقم 2 أدناه، أن متوسط موافقة عينة الدراسة حول مدى تطبيق المصارف الإسلامية لمبادئ الحوكمة تراوحت بين نسبة 69.9\% و64.5\%، وهي نسبة متوسطة تقتضي

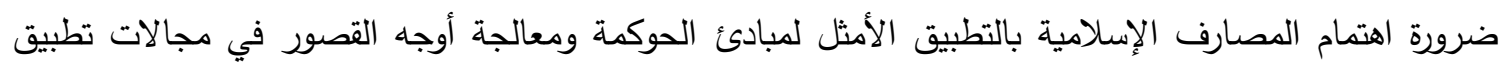
تلك المبادئ.

جدول رقم (2) ملخص نتائج الاستبيان حسب المتغيرات ودرجة موافقة العينة

\begin{tabular}{|c|c|c|c|c|c|c|c|}
\hline \multirow[t]{2}{*}{ الحكم } & \multicolumn{2}{|c|}{ 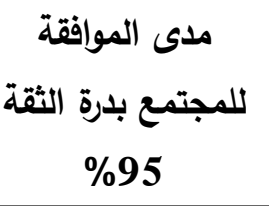 } & \multirow{2}{*}{ الموافقة } & \multirow{2}{*}{ المعياري } & \multirow[t]{2}{*}{ المتوسط } & \multirow[t]{2}{*}{ المحاور } & \multirow[t]{2}{*}{ الرتبة } \\
\hline & النسبة & النسبة & & & & & \\
\hline كبوفة كبيرة & $\begin{array}{c}72.3 \\
\%\end{array}$ & $\% 78.3$ & $\% 75.3$ & 0.794 & 3.765 & 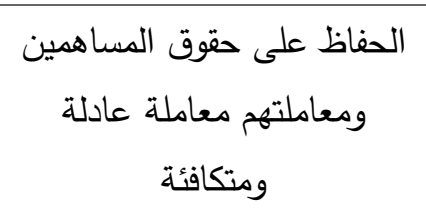 & 1 \\
\hline متوفرة & $\begin{array}{c}64.6 \\
\%\end{array}$ & $\% 71.5$ & $\% 68.1$ & 0.919 & 3.404 & والثفافية بالنسبة للبيانات المالية & 2 \\
\hline
\end{tabular}




\begin{tabular}{|c|c|c|c|c|c|c|c|}
\hline كبيرة & & & & & & المنشورة & \\
\hline متوفرة & $\% 60$ & $\% 66.1$ & $\% 63.1$ & 0.809 & 3.154 & مجلس الإدارة والإدارات التتفيذية ومدؤليات & 3 \\
\hline متوفرة & $\% 57$ & $\% 64.3$ & $\% 60.6$ & 0.969 & 3.031 & الحفاظ على حقوق أصحاب & 4 \\
\hline متوفرة متوسطة & $\begin{array}{c}64.5 \\
\%\end{array}$ & $\% 69.9$ & $\% 67.2$ & 0.721 & 3.359 & المتوسط العام للاستبيان & \\
\hline
\end{tabular}

وقد جاءت النتائج التحليلية لاختبار فرضيات الدراسة الأربع على النحو التالي:

1.

كما هو موضح في الجدول رقم 2، أن فرضية الحفاظ على حقوق المساهمين ومعاملتهم معاملة عادلة ومتكافئة جاء بمتوسط 3.765 وبدرجة موافقة 75.3\%، وهو ما يعنى أن الحفاظ على حقوق المساهمين ومعاملتهم معاملة عادلة ومتكافئة متوفر بدرجة كبيرة في المصارف الإسلامية، إلا أنه يوجد بعض إنه

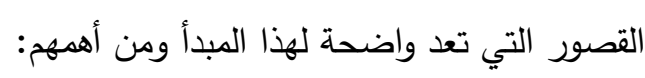
تدنى مستوى العدالة في نظام الرواتب والأجور للعاملين في البنك الإسلامي مقارنة مع البنوك

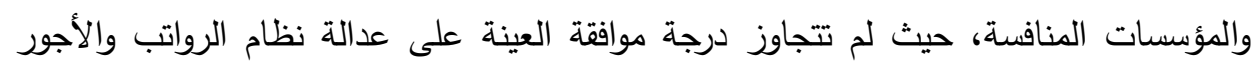

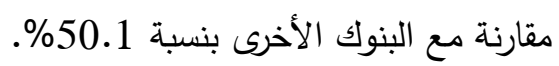
هدنى كفاءة وفاعلية قنوات الاتصال الخاصة بتوصيل المعلومات لندات المناسبة لأصحاب المصالح، إذ بلغت درجة الموافقة في حرص إدارة البنك على توفير المعلومات المناسبة لأصحاب المصالح

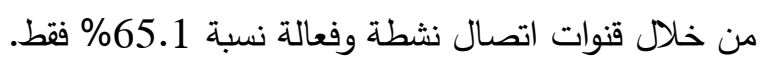
2. نتائج اختبار صحة الفرضية الثانية

وفقا للجدول السابق فإن فرضية توفير متطلبات الإفصاح والثفافية بالنسبة للبيانات المالية المنشورة جاءت بمتوسط 3.404 وبدرجة موافقة 68.1\%، الأمر الذي يعنى أن توفير متطلبات الإفصاح والثفافية

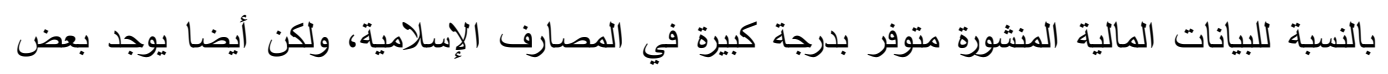

$$
\text { القصور في تطبيق هذا المبدأ واهمها: }
$$

• أن إدارة البنك لا تحرص على توفير معلومات كافية وشفافة عن أهدافها وخططها المستقبلية

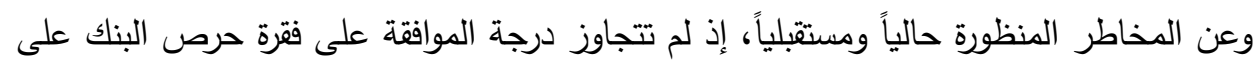

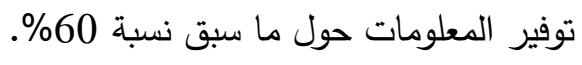

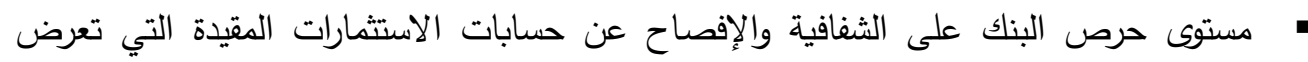
خارج الميزانية كانت متوسطة، إذ لم تتجاوز درجة الموافقة في أن البنك يحرص على على الإفصاح

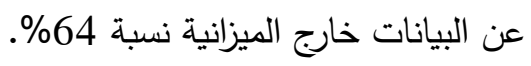


• القصور النسبي في نشر البنك لبياناته المالية التي تخضع لشروط الإفصاح العام بشكل دوري وبشفافية ومدققة وفقاً للمعايير الدولي الأخرى، إذ وصلت درجة الموافقة على هذه الفقرة إلى نسبة لئه

\% 977.1

3. نتائج اختبار صحة الفرضية الثالثة

وفيما يتعلق بغرضية تحديد صلاحيات ومسئوليات مجلس الإدارة، والإدارات التتفيذية، وهيئات الرقابة الثرعية فقد جاءت بمتوسط 3.154 وبدرجة موافقة 63.1\%، وهذا يعنى أن تحديد صلاحيات ومسئوليات

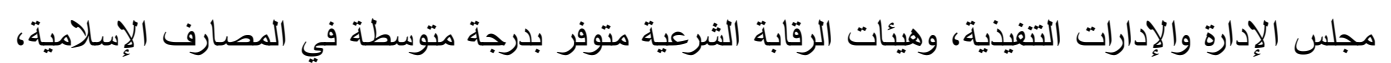
ويمكننا التعرف على أسباب تدنى مستوى التطبيق لهذه الفرضية من خلال النتائج الفرعية الأتية: • تقوم إدارة البنك بإعطاء دورات تدريبية للعاملين فيها للتعريف بمبادئ الحوكمة وكيفية تحقيقها: جاءت هذه الفقرة بمتوسط 2.248 وبدرجة موافقة 45\% باعط دوراء

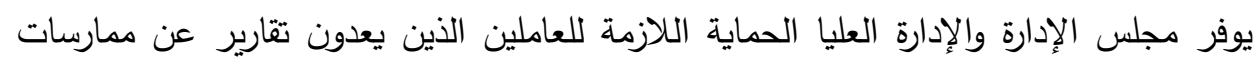

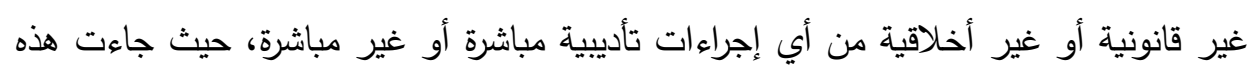

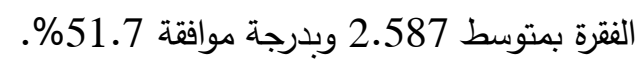
يحدد النظام الداخلي للبنك بوضوح الصلاحيات والواجبات الخاصة بمجلس الإدارة: جاءت هذه

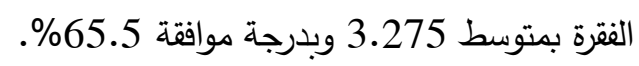
" وجود قنوات اتصال واضحة بين هيئة الرقابة الشرعية والأجهزة الرقابية الأخرى وأهمها لجنة

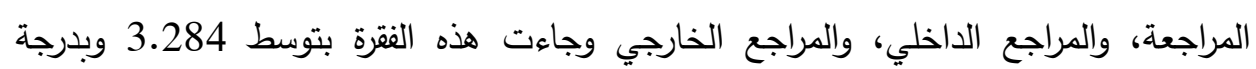

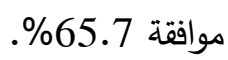
يلتزم أعضاء مجلس الإدارة باللوائح والتعميمات التي يصدرها البنك المركزي بخصوص تمويل

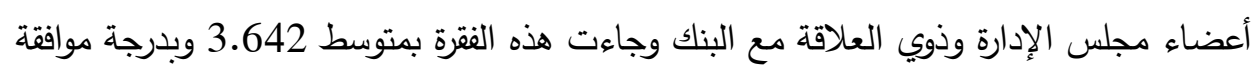
.\%72.8 تقوم هيئة الرقابة الثرعية بوضع نماذج العقود ومراجعة العمليات الاستثمارية وإصدار الفتوى في

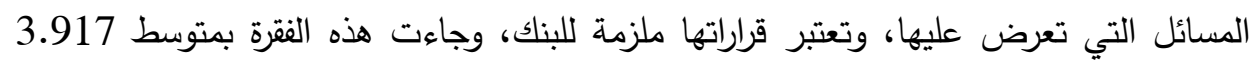

$$
\text { 4. نتائج اختبار صحة الفرضية الرابعة 78.3\% }
$$

وفيما يخص فرضية الحفاظ على حقوق أصحاب المصالح، فإن نتائج التحليل توضح أنها جاءت بمتوسط 3.031 وبدرجة موافقة 60.6\% وهذا يعنى أن الحفاظ على حقوق أصحاب المصالح متوفر بدرجة متوسطة في المصارف الإسلامية، وكانت أوجه القصور في أداء الفرضية كالتالي: تتوفر العدالة في نظام الرواتب والأجور للعاملين في البنك بالمقارنة مع البنوك والمؤسسات المنافسة، وجاءت هذه الفقرة بمتوسط 2.505 وبدرجة موافقة 50.1

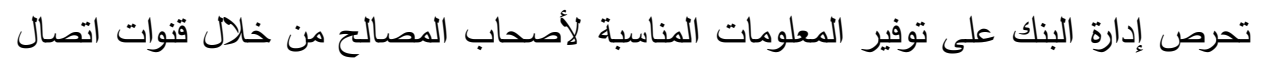

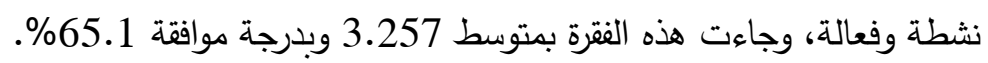
تلتزم إدارة البنك بحقوق أصحاب المصالح المحددة لهم بموجب اللوائح والقوانين، بما في ذلك ولك تعويضهم عن أي أضرار تلحق بهم، وجاءت هذه الفقرة بمتوسط 3.330 وبدرجة موافقة 
ظهر مفهوم الحوكمة المؤسسية عالمياً نتيجة انهيار وإفلاس بعض المؤسسات العالمية الكبرى، ولأن المفهوم جذب انتباه جميع الاقتصاديين على المستوى الدولي والإقليمي والمحلي ، فمن الضروري تفعيل تكاثف جهود المؤسسات والمنظمات الدولية في مجال تفعيل دور وأهمية الحوكمة المؤسسية، وبعد التعرف على طبئ وليعة حوكمة المؤسسات

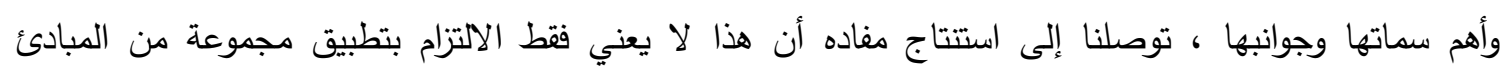

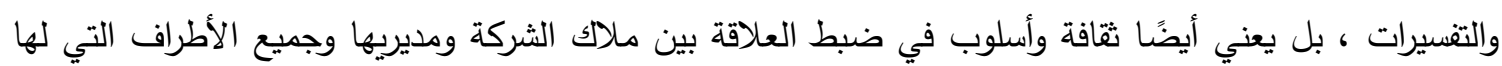
علاقة بها أو لها مصلحة فيها ومعها.

لذلك تحاول العديد من الدول تبني مفهوم الحوكمة وتطبيق مبادئه على قطاع الأعمال بصفة عامة وخاصة القطاع المصرفي ، لأن القطاع المصرفي هو أساس أي نشاط ونظام اقتصادي لأنه يوفر الأموال لجميع الأنشطة الأنس

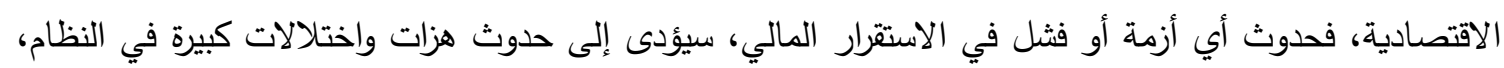

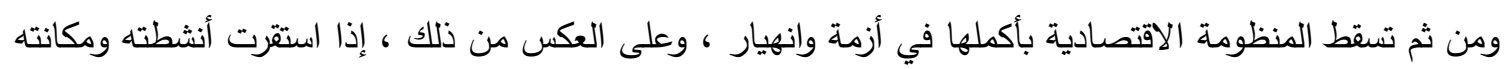

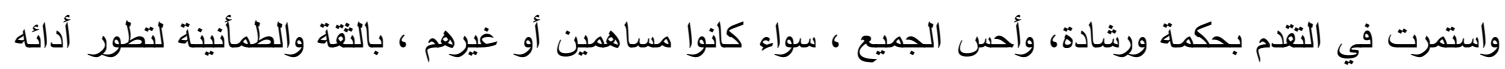
وزيادة الربحية ، وكل ذلك له تأثير إيجابي على المنظومة الاقتصادية.

نتائج الاراسة

من خلال دراستتا للجانب النظري توصلنا إلى مجموعة من النتائج يمكن تلخيصها فيما يلي:

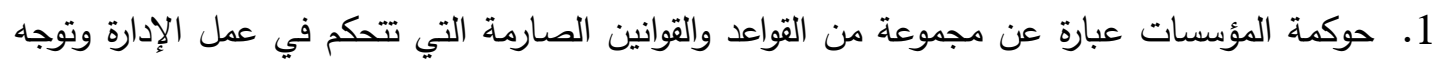
أدائها من أجل حماية حقوق جميع الأطراف ذات الصلة بالمؤسسة، خاصة المساهمين وأصحاب الديون. 2. أصبحت درجة التزام البنوك والمؤسسات بتطبيق مبادئ حوكمة المؤسسات أحد المعايير التي يجب على على دألى

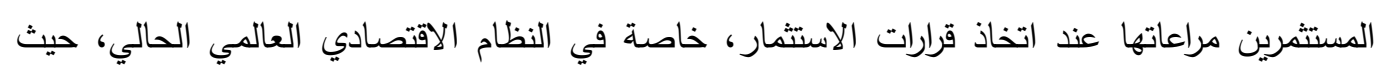
تتميز الأسواق المحلية والدولية بقدرة تنافسية عالية. 3. لا يقتصر دور الحوكمة على صياغة القواعد والقوانين ومراقبة تتفيذها، بل يشمل أيضًا توفير البيئة اللازمة لاعم مصداقيتها. 4. من الضروري تطبيق مبادئ حوكمة المؤسسات في البنوك الإسلامية، وذلك لتجنب أي شك من خلال صياغة العقد بالتفصيل وتحديد شروطها وأحكامها بدقة، من الناحيتين الدينية والتنظيمية. 5. إذا نجح مدير المصرف الإسلامي في تحقيق الهدفين في نفس الوقت، الهدف المالي الذي يلبي احتياجات المستثمرين، والهدف الديني لصحة العمليات المصرفية من منظور الثريعة الإسلامية.

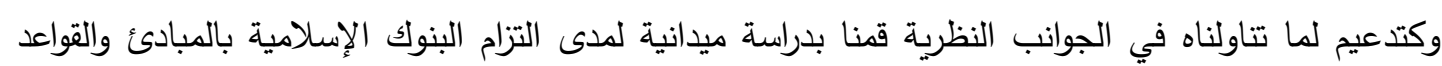
المتعارف عليها للحوكمة المؤسسية حيث توصلنا إلى مجموعة النتائج التالية: 6. أظهرت نتائج الدراسة أن المصارف الإسلامية بثكل عام تطبق مبادئ الحوكمة المتعارف عليها مع

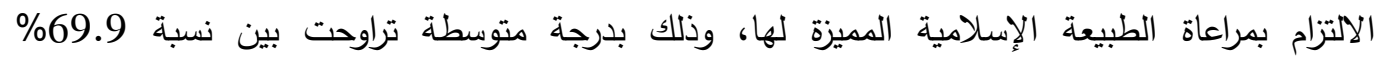

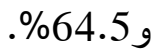

7. أظهرت نتائج الدراسة أن المصارف الإسلامية تلتزم بمبدأ الحفاظ على حقوق المساهمين فيها ومعاملتهم

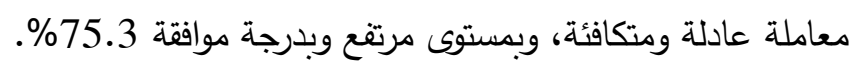


8. أظهرت نتائج الدراسة أن الدصارف الإسلامية تقوم بالحفاظ على حقوق أصحاب الدصالح، وأن درجة

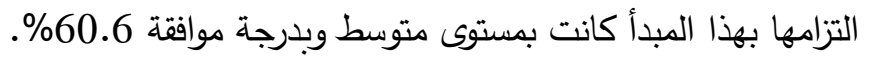
9. وضحت النتائج عدم العدالة في نظام الرواتب والأجور للعاملين، إذ بينت أن موافقة أفراد العينة على ذلك كانت بدرجة 50.1\% وبتقدير لفظي موافق بدرجة قليلة. 10. أظهرت نتائج الدراسة أن المصارف الإسلامية توفر متطلبات الإفصاح والثفافية بالنسبة للبيانات المالية

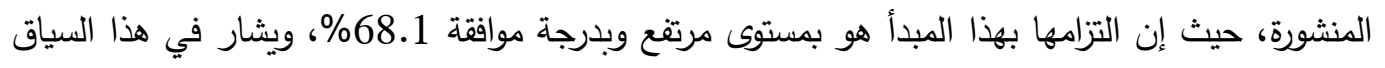

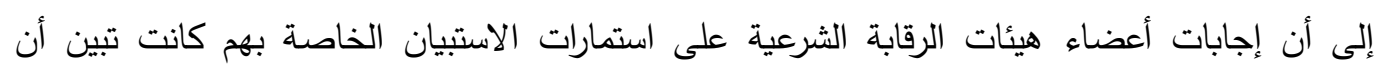

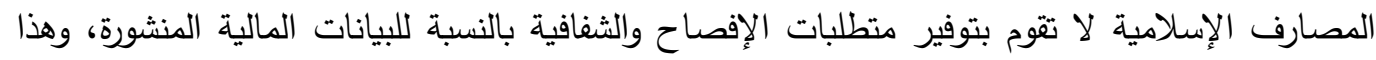
يدل على أن المصارف الإسلامية لا تقوم بتوفير متطلبات الإفصاح والثفافية للبيانات المالية الخاصة لإنة

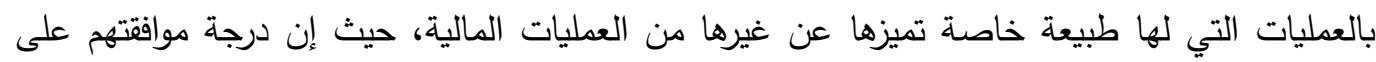
ذلك كانت 22.5\% وبتقدير لفظي لا أوافق.

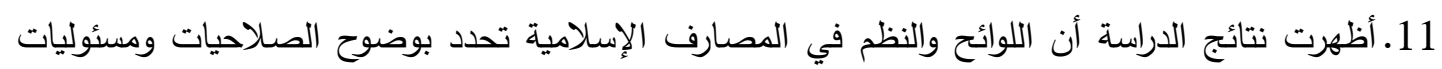

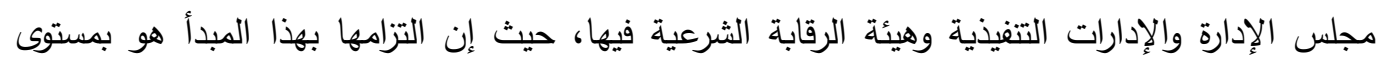
متوسط وبدرجة موافقة 63.1\% مالادل توصيات الاراسة

1. في خضم الحديث عن الحوكمة المؤسسية في المنظومة المصرفية يطرح موضوع تطبيقات الحوكمة

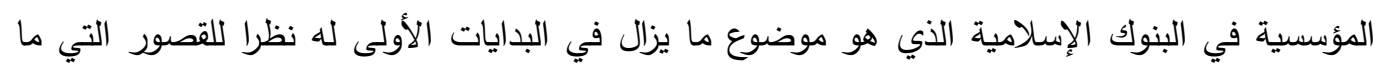

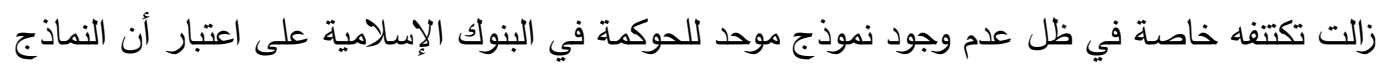

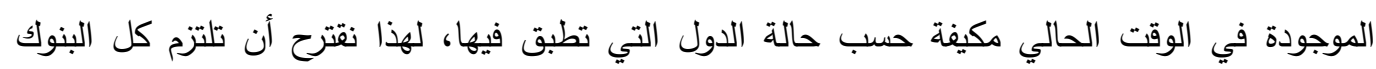
الاسلامية بإنشاء لجان للحوكمة تهتم بالتخطيط والتوجيه ومراقبة نسق الحوكمة بداخلها وتصحيح الانحرافات إذا لزم الامر ذلك، هذه اللجنة تكون مدعومة بلجان أخرى تسهل عملها كلجنة المراجعة التي بأي تشرف على كل التعينات الخاصة بالمراجعين ومتابعتهم، ولجنة المكافآت وغيرها.

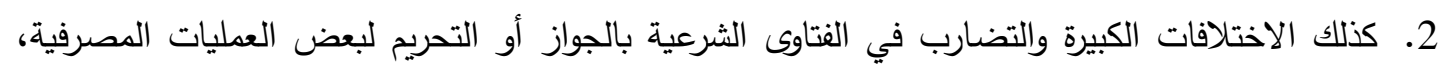
وعدم وجود هيئة رقابية شرعية موحدة، يستدعي التفكير في انثاء مرجعية واحدة مستقلة تراجع وتراقب عمل البنوك الاسلامية وتستقبل التقارير الثرعية منها. 3. زيادة الاهتمام بمراجعة اللوائح والنظم المنظمة لها بحيث تكفل هذه اللوائح والنظم التحديد الواضح والسليم للصلاحيات والمسؤوليات لكل من مجلس الإدارة والإدارات التنفيذية وهيئة الرقابة الثرعية فيها.

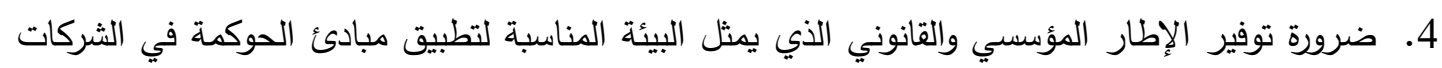
والمؤسسات المالية والمصرفية وخاصة منها البنوك الاسلامية؛ 5. نشر مفهوم وثقافة الحوكمة لاى كافة الموظفين العاملين في البنوك المركزية، وهذا بإصدار نشرات دورية

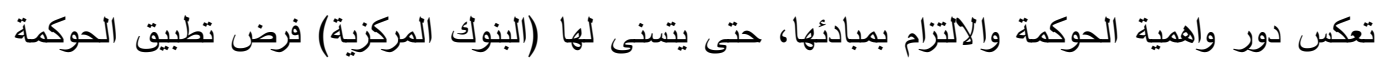
على كل المصارف الموجودة ضمن نطاقها؛ 6. المزيد من الدراسات والبحوث من المتخصصين حول الحوكمة وخاصة منها المصرفية بشكل عام. 
أبو عبيدة الطيب سليمان، الحوكمة في المصارف الإسلامية، بنك فيصل الإسلامي السوداني، 2016م.

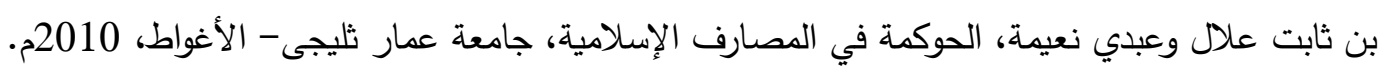

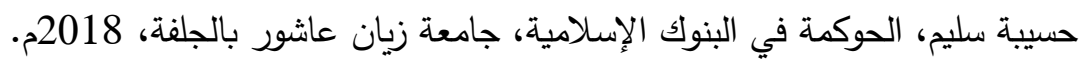

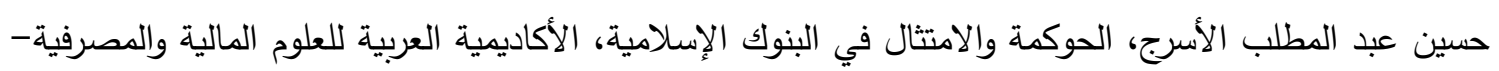

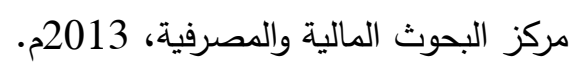

حسين عبد المطلب الأسرج، الحوكمة والامتتال في البنوك الإسلامية، مجلة الدراسات المالية والدصرفية- العدد

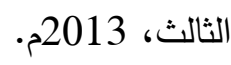

حسين محمد سمحان، الحوكمة في المصارف الإسلامية، مركز عبد الرحمن السديري الثقافي، 2011م.

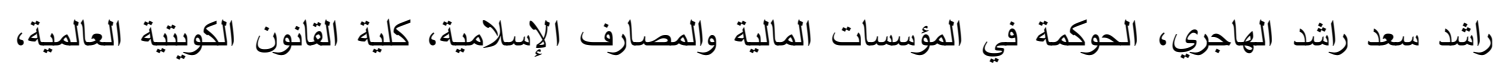
2016 رفيق، يوسف (2018)، تطبيق الحوكمة في المؤسسات المالية الإنسلامية: تجربة البنك الإنلامي الأردني، جامعة

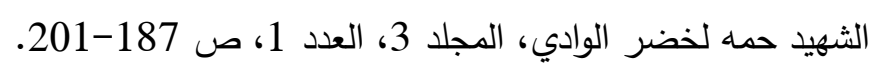

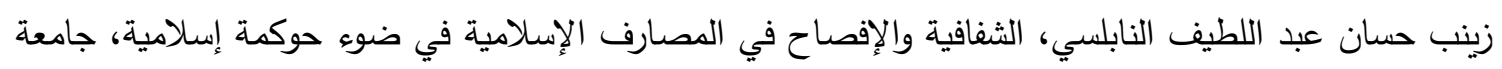
العلوم الإسلامية العالمية- رسالة دكتوراه، 2013م.

زينب، النابلسي (2020)، الحوكمة في الدصارف الإسلامية، الهيئة العالمية للتسويق الإسلامي.

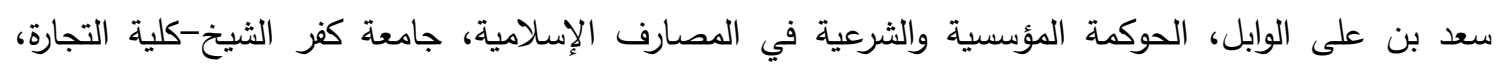
2015م.

سعد بن على الوابل، الحوكمة المؤسسية والثرعية في المصارف الإسلامية، جامعة الإمام بن سعود الإسلاميةكلية الاقتصاد والعلوم الإدارية، 2015م. العركائ

شوقي بورقبة، الحوكمة في المصارف الإنسلامية، كلية العلوم الاقتصادية وعلوم التسيير جامعة فرحات عباس -

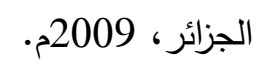

الطاهر خليفة عبد السلام الأسود، الحوكمة في المصارف من منظور إسلامي، المؤسسة العربية للاستثارات

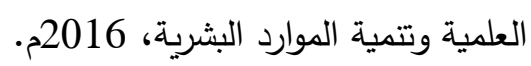

عبد الرحمن إبراهيم زيد الكيلاني، حوكمة الرقابة الثرعية في المؤسسات المالية الإنلامية، جامعة الكويت- مجلس النشر العلمي، 2017م.

قرقاد عادل، متطلبات حوكمة المصارف الإسلامية، مركز البحث وتطوير الموارد البشرية ماح وجامعة العلوم

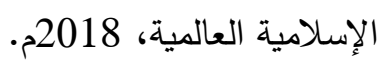

كعلة مريم، دور الحوكمة المؤسسية في تطوير الصناعة المصرفية الإسلامية: دراسة حالة شركة الراجحي

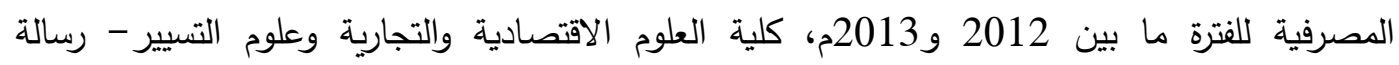

$$
\text { ماجستير، 2014م. }
$$

لخضر مرغاد وصليحة جعفر ، واقع الحوكمة في البنوك الإسلامية: دراسة حالة مجموعة البركة المصرفية خلال

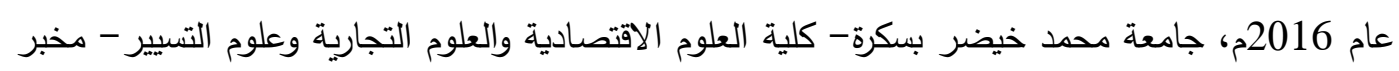
مالية، 2018م. 


$$
\begin{aligned}
& \text { محمد الحسين، الحوكمة في البنوك الإسلامية، جامعة عجمان-كلية القانون، 2014م. } \\
& \text { ملوكة برورة، الحوكمة في المصارف الإسلامية كضابط للابتكار والتطوير : نموذج البنوك الإسلامية الماليزية، }
\end{aligned}
$$

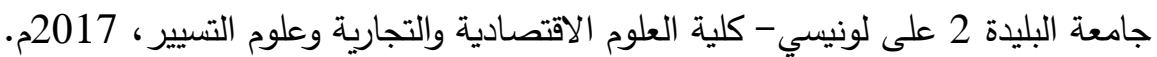

\section{References}

Abu Ubaidah Al-Taye, S. (2016). Governance in Islamic banks. Faisal Islamic Bank of Sudan. (in Arabic)

Alareeni, B. (2018). Does corporate governance influence earnings management in listed companies in Bahrain Bourse?. Journal of Asia Business Studies, 12(4), 551-570. https://doi.org/10.1108/JABS-06-2017-0082

Al-Asraj, H. (2013). Governance and compliance in Islamic banks. Arab Academy for Banking and Financial Sciences - Center for Banking and Financial Research. (in Arabic)

Al-Asraj, H. (2013). Governance and compliance in Islamic banks. Journal of Banking and Financial Studies, (3). (in Arabic)

Al-Aswad, A. (2016). Governance in banks from an Islamic perspective. Arab Foundation for Scientific Consulting and Human Resources Development. (in Arabic)

Al-Hajri, R. (2016). Governance in financial institutions and Islamic banks. Kuwait International Law College. (in Arabic)

Al-Hussein, M. (2014). Governance in Islamic banks. Ajman University - College of Law. (in Arabic)

Al-Kilani, A. (2017). Sharia governance in Islamic institutions. Kuwait University Academic Publication Council. (in Arabic)

Al-Nabulsi, Z. (2013). Transparency and disclosure in Islamic banks in the light of Islamic governance [Doctoral Dissertation]. International Islamic Sciences University - PhD Thesis. (in Arabic)

Al-Nabulsi, Z. (2020). Governance in Islamic banks. International Organization for Islamic Marketing. (in Arabic)

Al-Wabel, S. (2015). Institutional and Sharia governance in Islamic banks. Kafr El Sheikh University - College of Commerce. (in Arabic)

Al-Wabel, S. (2015). Institutional governance and Sharia in Islamic banks. Imam bin Saud Islamic University - College of Economics and Administrative Sciences. (in Arabic)

Bin Thabit, A., \& Abdi, N. (2010). Governance in Islamic banks. Ammar Thleiji University - Laghouat. (in Arabic)

Hasan, A.N., M. (2019). Public governance and economic growth: Conceptual framework. International Journal of Business Ethics and Governance, 2(2), 1-15. https://doi.org/10.51325/ijbeg.v2i2.21

Kaala, M. (2014). The role of institutional governance in the development of the Islamic banking industry: A Case Study of Al-Rajhi Banking Corporation for 
the period between 2012 and 2013 [Master's thesis]. College of Economic, Commercial and Management Sciences - Master's thesis. (in Arabic)

Malouka, B. (2017). Governance in Islamic banks as a control for innovation and development: The Malaysian Islamic banking model. University of Blida 2 Ali Lunisi - College of Economic, Business and Management Sciences. (in Arabic)

Marghad, L., \& Jaafar, S. (2018). The status of governance in Islamic banks: A case study of Al Baraka banking group in 2016. Muhammad Khader University of Biskra - College of Economic Sciences, Commercial Sciences and Management Sciences - Financial Lab. (in Arabic)

Qarqad, A. (2018). Governance requirements for Islamic banks. Center for Research and Development of Human Resources and the International Islamic Sciences University. (in Arabic)

Rafik, Y. (2018). Application of governance in Islamic financial institutions: The experience of the Jordan Islamic bank. Shaheed Rafik Lakhdar Al-Wadi University, 3(1), 187-201. (in Arabic)

Salman, M., \& Laouisset, J. (2020). The governance in the corporate excellence model The 4th generation model. International Journal of Business Ethics and Governance, 3(2), 73-95. https://doi.org/10.51325/ijbeg.v3i2.34

Samhan, H. (2011). Governance in Islamic banks. Abdul Rahman Al-Sudairy Cultural Center. (in Arabic)

Selim, H. (2018). Governance in Islamic banks. Zian Ashour University Djelfa. (in Arabic)

Shawky, B. (2009). Governance in Islamic banks. Faculty of Economic Sciences and Management Sciences, Farhat Abbas University - Algeria. (in Arabic) 